\title{
Status report for optimization and engineering
}

\author{
Nikolaos V. Sahinidis ${ }^{1}$
}

Received: 10 October 2019 / Revised: 10 October 2019 / Accepted: 10 October 2019 /

Published online: 18 October 2019

(c) Springer Science+Business Media, LLC, part of Springer Nature 2019

As this issue marks the end of my second year as editor-in-chief of Optimization and Engineering (OPTE), I am delighted to provide a brief status report for our journal.

OPTE launched with the intent to provide a forum for researchers to learn about new developments in optimization and challenging and successful applications of optimization in engineering. The founding editor, Tamás Terlaky, was the first editor-in-chief from 1999 to 2012 and was succeeded by Miguel F. Anjos, who led OPTE from 2013 to 2017 . The journal appeals to both engineers and mathematicians and is served by an editorial board of about 60 individuals, half of them from various engineering fields, and the others from mathematics, operations research, and related disciplines.

Since its inception, the journal has achieved many milestones and streamlined its operations. Major highlights of our progress are summarized as follows:

- During its first year, OPTE published 20 articles. Currently, we publish over 40 articles per year.

- OPTE has published special issues on important topics, including surrogate modeling and optimization (Bandler and Madsen 2001; Bandler et al. 2008; Audet et al. 2004), mixed-integer programming (Grossmann and Sahinidis 2003), multidisciplinary design (Alexandrov 2005), optimization under uncertainty (Romero and Chen 2006), optimization and control (Fukushima and Wang 2007), system sciences and optimization (Volume 10, Issue 2, 2009), optimization and engineering applications (Martins and Kostina 2010; Herskovits et al. 2011), applications of variational inequality problems (Tawhid 2012), advanced algorithms (Bertók et al. 2013), blackbox and derivative-free optimization (Audet and Kokkolaras 2016), optimization in the oil and gas industry (Furman et al. 2017), optimization for financial engineering (Kwon and Zenios 2017), PDE-constrained optimization (Ulbrich1 and van Bloemen Waanders 2018), mixedinteger nonlinear programming (Sahinidis 2019), and enterprise-wide optimization (Gounaris and Grossmann 2019). Upcoming special issues are devoted to MOPTA, technical operations research, multiobjective optimization, optimization in space engineering, and sustainable development of energy, water and environmental systems.

Nikolaos V. Sahinidis

sahinidis@cmu.edu

1 Department of Chemical Engineering, Carnegie Mellon University, Pittsburgh, PA, USA 
- Since 2015, OPTE awards the annual Rosenbrock Best Paper Prize, named after Howard Rosenbrock, for his excellent contributions in bridging the gap between optimization and engineering (Anjos 2015).

- Since January 1, 2018, OPTE's rejection rates are over $83 \%$, and the average time to first decision for accepted manuscripts is 109 days.

- The journal has consistently ranked in the top two quartiles of optimization journals and journals in various engineering fields.

- OPTE's impact factor reached 1.824 this past year.

A healthy inventory of OPTE articles is currently in line for print, and the publisher encourages us to grow our publishing rates. Submissions to our journal are of sufficient quality and volume to allow us to increase the number of papers we publish. As OPTE continues to provide a forum for researchers in both engineering and optimization, I encourage submissions of high-quality papers exploring optimization algorithms, software, and theory, and the interfaces between optimization and engineering.

\section{References}

Alexandrov N (2005) Editorial-Multidisciplinary design optimization. Optim Eng 6:5-7

Anjos MF (2015) Announcement: inaugural Howard Rosenbrock prize. Optim Eng 16(3):507-509

Audet C, Kokkolaras M (2016) Blackbox and derivative-free optimization: theory, algorithms and applications. Optim Eng 17:1-2

Audet C, Dennis JE, Vicente LN (2004) Editorial. Optim Eng 5:99-100

Bandler JW, Madsen K (2001) Editorial-Surrogate modelling and space mapping for engineering optimization. Optim Eng 2:367-368

Bandler JW, Koziel S, Madsen K (2008) Editorial-Surrogate modeling and space mapping for engineering optimization. Optim Eng 9:307-310

Bertók B, Süle Z, Terlaky T (2013) Veszprém optimization conference: advanced algorithms (VOCAL) 2010. Optim Eng 14:501-502

Fukushima M, Wang S (2007) Editorial. Optim Eng 8:239-240

Furman KC, El-Bakry AS, Song J-H (2017) Optimization in the oil and gas industry. Optim Eng 18:1-2

Gounaris ChE, Grossmann IE (2019) A preface to the special issue on enterprise-wide optimization. Optim Eng 20:965-968

Grossmann IE, Sahinidis NV (2003) Prologue. Optim Eng 4:5-6

Herskovits J, Rodrigues HC, Mota Soares CA, Sagastizábal CA, Secchi AR (2011) Editorial. Optim Eng $12: 1-3$

Kwon RH, Zenios SA (2017) Optimization for financial engineering: a special issue. Optim Eng 18:343-347 Martins JRRA, Kostina EA (2010) Editorial. Optim Eng 11:1-3

Romero V, Chen C-H (2006) Editorial: Special issue on optimization under uncertainty. Optim Eng 7:223-224

Sahinidis NV (2019) Mixed-integer nonlinear programming 2018. Optim Eng 20:301-306

Tawhid MA (2012) Special issue on applications of variational inequality problems. Optim Eng 13:371-373

Ulbrich M, van Bloemen Waanders B (2018) An introduction to partial differential equations constrained optimization. Optim Eng 19:515-520

Publisher's Note Springer Nature remains neutral with regard to jurisdictional claims in published maps and institutional affiliations. 